\title{
Characterization of Nonlinearities in a Class-J Power Amplifier
}

\author{
Branko Bukvić, Member, IEEE and Milan M. Ilić, Senior Member, IEEE
}

\begin{abstract}
We characterize the nonlinearities of our previously designed $10 \mathrm{~W}$ class-J power amplifier with a carrier at $1.5 \mathrm{GHz}$. We employ numerical simulations and real time adjacent channel power ratio (ACPR) measurements on the fabricated prototype. The measurements are performed for a wideband code division multiple access (WCDMA) signal with $10.5 \mathrm{~dB}$ peak-to-average power ratio (PAPR) and 3.84 MHz bandwidth.
\end{abstract}

Key words - ACPR, class-J, high-efficiency, microwave power amplifier, nonlinearities.

\section{INTRODUCTION}

New concepts in wireless telecommunication systems, such as Software defined radio and Cognitive radio [1], yielded numerous benefits for end users. At the transmitter side, a power amplifier (PA) is the key element which consumes the most power and injects the greatest amount of impurities in the transmitted signal. This, in turn, can be the source of errors in the embedded information at the receiver side. The impurities, generated by the $\mathrm{PA}$, come as consequences of various physical effects. However, they are all commonly classified as PA nonlinearities. These nonlinearities are described and quantified in different ways, the most common of which are: intermodulation products (IM), spectral regrowth, error vector magnitude (EVM) and adjacent channel power ratio (ACPR) [2].

Class-J mode of operation in PAs is recently gaining popularity because it practically maintains very good linearity within class-B biasing conditions and efficiency [3]-[4]. In this paper, we report the results of the most important nonlinear characterizations of our $10 \mathrm{~W}$ class-J PA designed utilizing the novel technique presented in [5],

Paper received April 23, 2018; revised August 2, 2018; accepted August 15, 2018. Date of publication December 25, 2018. The associate editor coordinating the review of this manuscript and approving it for publication was Prof. Aleksandar Nešković.

This paper is a revised and expanded version of the paper presented at the 25th Telecommunications Forum TELFOR 2017 [9].

This work was supported by the Serbian Ministry of Education, Science, and Technological Development under Grant TR-32005.

Branko Bukvić is with IMTEL Komunikacije a.d., Bulevar Mihajla Pupina 165b, 11070 Novi Beograd, Belgrade, Serbia (e-mail: bukvic.branko@gmail.com).

Milan Ilić is with the School of Electrical Engineering, University of Belgrade, Bulevar Kralja Aleksandra 73, 11120 Belgrade, Serbia (phone: +381-11-3218329; fax: +381-11-3248681; e-mail: milanilic@etf.bg.ac.rs). thus verifying theoretical predictions of the proposed method, as well as the benefits of class-J operation in general.

In Section II, basic theory about Class-J amplifier and PA characteristics are presented, without nonlinearity considerations. Section III shows the measured and simulated results of the output spectrum and $3^{\text {rd }}$ order intermodulation products. Also shown are the spectra of the quadrature amplitude modulation (QAM) and orthogonal frequency-division multiplexing (OFDM) signals at the input and output of the PA. In Section IV, measured ACPR results are presented.

\section{THEORY OF THE CLASS-J POWER AMPLIFIER}

To specify the exact mode of PA operation, to which the characterization of nonlinearities in this work pertains, we here present the most important results of the novel Class-J amplifier design reported in [5].

In Fig. 1 the transistor is modelled as an ideal voltagecontrolled current source in parallel with the capacitor having the finite capacitance $C$. DC power is supplied through an inductor of infinite inductivity $L$. LC filter allows only the fundamental frequency signal to pass through and the load impedance $Z$ has both real and imaginary parts, $R$ and $X$.

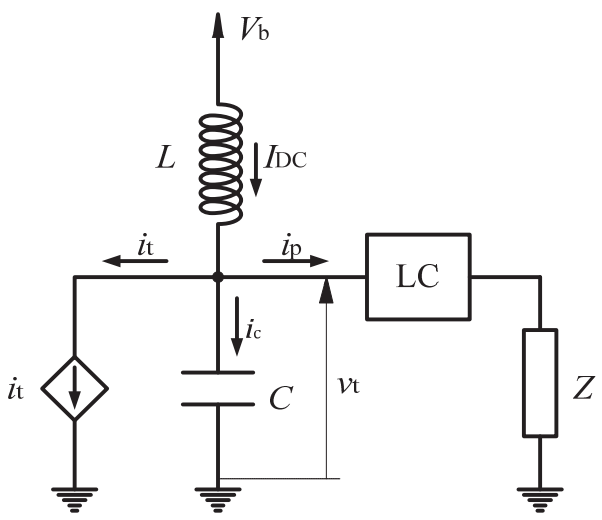

Fig. 1 Simplified amplifier output circuit schematic for Class-J analysis.

The transistor current $i_{\mathrm{t}}$ is given in the form

$$
i_{\mathrm{t}}=I_{\mathrm{m}} \frac{\sin (\theta)+|\sin (\theta)|}{2} .
$$

Here, $\theta=2 \pi f t$, where $f$ is the frequency, $t$ is the time and $I_{\mathrm{m}}$ is transistor maximum current. Due to LC filter action, the load current $i_{\mathrm{p}}$ has only the fundamental frequency component

$$
i_{\mathrm{p}}(\theta)=I_{1} \cos (\theta+\varphi)
$$


with $I_{1}\left(I_{1} \geq 0\right)$ as the amplitude and $\varphi$ as the initial phase of $i_{\mathrm{p}}$. The transistor voltage $v_{\mathrm{t}}$ (this voltage is the same as the voltage on capacitor $\mathrm{C}$ ) can be calculated as

$$
\begin{aligned}
v_{\mathrm{t}}(\theta) & =\frac{1}{\omega C} \int_{0}^{\theta}\left(\frac{I_{\mathrm{m}}}{\pi}-I_{\mathrm{m}} \frac{\sin (\tau)+|\sin (\tau)|}{2}\right. \\
& \left.-I_{1} \cos (\tau+\varphi)\right) \mathrm{d} \tau+V_{\mathrm{t}, 0} .
\end{aligned}
$$

Here, $V_{\mathrm{t}, 0}$ is the voltage at $\theta=0$. The $\mathrm{DC}$ value of $v_{\mathrm{t}}$ is adjusted in a way that the minimum of $v_{\mathrm{t}}$ does not go below 0 . So, $V_{\mathrm{t}, 0}$ can be excluded from further analysis.

Following the derivations in the frequency domain, where only fundamental frequency component is assumed, the optimal $I_{1}$ and $Z$ (in the sense of maximum efficiency) are determined as

$R=\frac{1}{\omega C} \frac{\cos (\alpha) \cos (\varphi)}{\sin (\alpha+\varphi)}, R \geq 0, X=\frac{1}{\omega C} \frac{\sin (\alpha) \cos (\varphi)}{\sin (\alpha+\varphi)}$

$I_{1}=\frac{1}{2} I_{\mathrm{m}} \frac{\sin (\alpha+\varphi)}{\cos (\alpha)}, I_{1} \geq 0$, where $\tan (\alpha)=\frac{X}{R}$.

The angle $\alpha$ is in the range $-\pi / 2$ to $\pi / 2(R \geq 0)$ and the angle $\varphi$ is taken to be in the range $-\pi$ to $\pi$. Parameters $I_{\mathrm{m}}$ and $\omega C$ are assumed to be independent constants.

The minimum, $V_{\mathrm{t} \text {,min }}$, of the voltage $v_{\mathrm{t}}$, was set to 0 , by simply changing the DC voltage. The DC value of $v_{\mathrm{t}}$ is the bias voltage $V_{\mathrm{b}}$, given as

$$
V_{\mathrm{b}}=\frac{1}{2 \pi} \int_{0}^{2 \pi} v_{\mathrm{t}}(\theta) \mathrm{d} \theta-V_{\mathrm{t}, \min } .
$$

If $I_{\mathrm{m}}=1 \mathrm{~A}$ and $1 / \omega C=1 \Omega$, the amplifier drain (collector) efficiency can be numerically calculated for the sets of values corresponding to angles $\alpha$ and $\varphi$.

The drain efficiency, (DE), is given as the ratio of the RF output power and the DC bias supply power:

$$
\mathrm{DE}=\frac{\pi}{8} \frac{1}{\omega C} \frac{I_{\mathrm{m}}}{V_{\mathrm{b}}} \frac{\cos (\varphi) \cdot \sin (\alpha+\varphi)}{\cos (\alpha)} .
$$

For known $V_{\mathrm{b}}$, the drain efficiency was calculated for every node of the discrete mesh made of angles $\alpha$ and $\varphi$. Fig. 2 shows a 3-D plot of the drain efficiency vs angles $\alpha$ and $\varphi$. Even with the angle $\alpha$ constrained to the interval $-\pi / 2$ to $\pi / 2$, the resistance $R$ can still be negative, from (4). This "negative $R$ " region was set to zero efficiency and it is colored in purple in Fig. 2. The same was done with "negative $I_{1}$ " region, from (4).
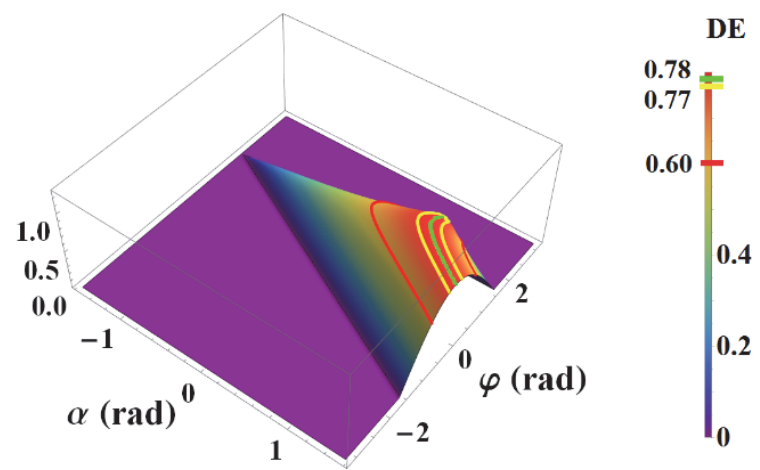

Fig. 2. Drain efficiency.

It can be seen from Fig. 2 that there exists a wide region where drain efficiency is above $60 \%$. This allows the use of a wide range of corresponding $R, X$ and $I_{1}$, as well as $\omega C$ and $I_{\mathrm{m}}$. Alternatively, if all these parameters are fixed at optimal values, the high efficiency is kept over a wider frequency range. This explains the Class-J amplifier's high immunity to fabrication tolerance of employed circuit components and/or wide bandwidth.

Using the obtained results as guidelines, the amplifier is designed by choosing $\alpha$ and $\varphi$ (e.g., from Fig. 2) which yield predetermined efficiency. Recalling that the efficiency, at this stage, corresponds to the normalized $I_{\mathrm{m}}=1 \mathrm{~A}$ and $1 / \omega C=1 \Omega$, we note that the bias voltage $V_{\mathrm{b}}$ is found from the normalized values as well. For any real desired transistor current amplitude $I_{\mathrm{m} \text {,new }}$ and bias voltage $V_{\mathrm{b} \text {,new, }}$, factor $1 / \omega C$ should be de-normalized as

$$
\left.\frac{1}{\omega C}\right|_{\text {new }}=\frac{V_{\mathrm{b}, \text { new }}}{V_{\mathrm{b}}} \frac{I_{\mathrm{m}}}{I_{\mathrm{m}, \text { new }}} \cdot 1 \Omega,
$$

and this automatically de-normalizes other parameters, i.e., $R$ and $X$.

The presented theory was verified on a PA prototype fabricated using Cree's CGH40010F transistor, with $40 \mathrm{dBm}$ of maximum saturated power. The input (IMN) and output matching network (OMN) were realized in the microstrip technology on a Rogers RT Duroid 5880 with the substrate thickness $h=1575 \mu \mathrm{m}$, metallization thickness $t=17 \mu \mathrm{m}$, relative dielectric permittivity $\varepsilon_{\mathrm{r}}=2.2$, and loss tangent $\tan \delta=0.0009$. A photograph of the fabricated PA is given in Fig. 3. The transistor gate bias voltage is $-2.8 \mathrm{~V}$ and its drain bias voltage is $20 \mathrm{~V}$. The quiescent drain current is $0.1 \mathrm{~A}$, where $I_{\mathrm{m}}=1 \mathrm{~A}$.

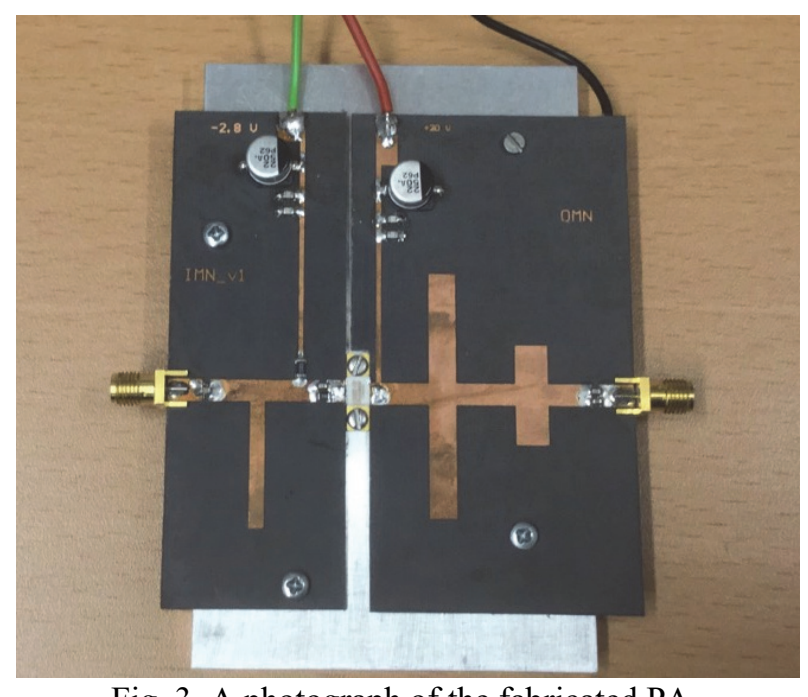

Fig. 3. A photograph of the fabricated PA.

By design, the PA was first biased in deep class-AB, its central operating frequency was set to $f=1.5 \mathrm{GHz}$, the $\mathrm{OMN}$ was then designed to ensure class-J operation and suppress the $2^{\text {nd }}$ harmonic, and the IMN was finally obtained through source-pull simulations. Simulated and measured small signal $S$-parameters, as well as gain, output power (Pout), and drain efficiency (DE) vs input power (Pin) are given in [5]. The $1 \mathrm{~dB}$ compression point corresponds to $35.6 \mathrm{dBm}$ output power and $55.2 \%$ drain efficiency. The $2 \mathrm{~dB}$ compression point corresponds to $38 \mathrm{dBm}$ output power and $70 \%$ drain efficiency. 


\section{CHARACTERIZATION OF NONLINEARITIES}

In Fig. 4 we present the measured output power spectrum of the PA driven close to $1 \mathrm{~dB}$ compression point. Note that a $30 \mathrm{~dB}$ attenuator was connected at the output during measurements in order to protect the spectrum analyzer. Hence, $30 \mathrm{~dB}$ should be added to the readings from Fig. 4 to obtain the actual output power. This single-tone analysis gives a good insight into the power level of the generated harmonics. We can see from the figure, that the second harmonic (marked as $\mathrm{m} 3$ ) is indeed suppressed by almost $50 \mathrm{~dB}$ in comparison with the signal at the fundamental frequency.

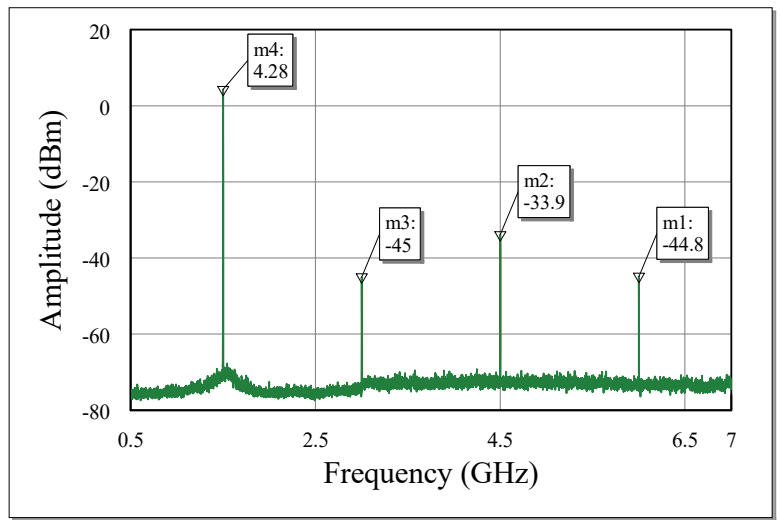

Fig. 4. Output power spectrum of the PA at nearly $1 \mathrm{~dB}$ compression point measured after a $30 \mathrm{~dB}$ attenuator.

As the next test for the nonlinear characterization of the PA, we employ a two-tone analysis to determine the $3^{\text {rd }}$ order intermodulation distortion (IM3). We set the central frequency to $1.5 \mathrm{GHz}$ and the separation between the two tones to $10 \mathrm{MHz}$. The results of the simulation are shown in Fig. 5. We can conclude from the figure that the $3^{\text {rd }}$ order intercept point $\left(\mathrm{IP}_{3}\right)$ is at $P_{\mathrm{IP} 3}=38.6 \mathrm{dBm}$ output power which corresponds to $17.76 \mathrm{dBm}$ input power.

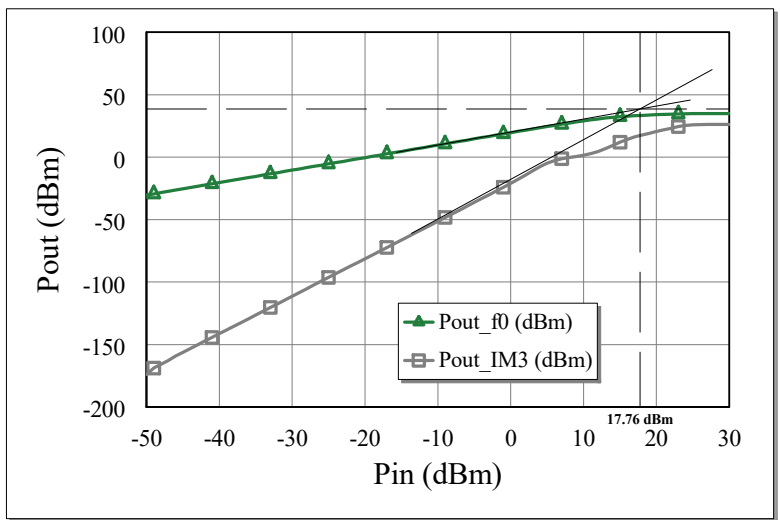

Fig. 5. Results of the simulated two-tone analysis.

As the second test, we use a QAM16 signal, with $10 \mathrm{MHz}$ bandwidth, at the amplifier input to modulate the carrier at $1.5 \mathrm{GHz}$. The obtained peak-to-average power ratio (PAPR) is about $6.2 \mathrm{~dB}$ and the input power level is $20 \mathrm{dBm}$. The results of this simulation are shown in Fig. 6. It can be concluded, based on the figure, that the difference between the maximum signal level in the main channel and the maximum signal level in the adjacent channel is, $\Delta P=20.05 \mathrm{dBm}$.

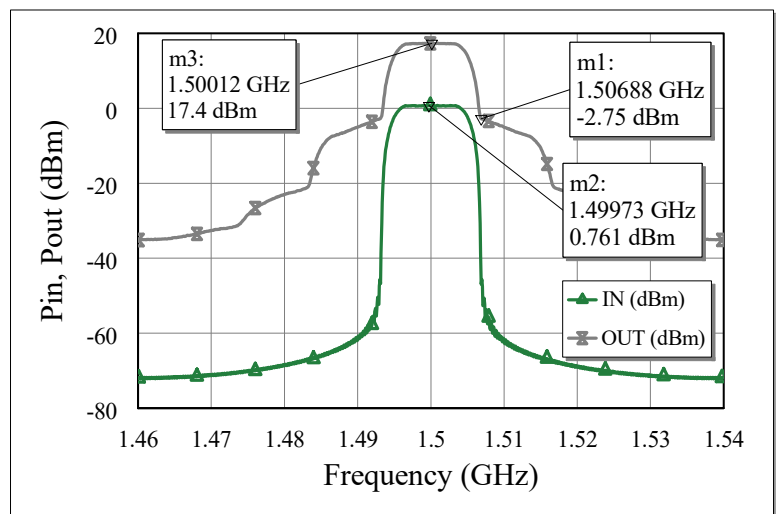

Fig. 6. Simulated spectra of the QAM16 signals at the input (green) and output (grey) of the amplifier.

As the third test, we similarly use the OFDM signal with 256 subcarriers at the PA input to modulate the $1.5 \mathrm{GHz}$ carrier. The input power is $18.2 \mathrm{dBm}$, the bandwidth of the employed OFDM signal is $10 \mathrm{MHz}$, and the obtained PAPR is about $13.2 \mathrm{~dB}$. The results of this simulation are shown in Fig. 7. From the figure we conclude that $\Delta P=15.8 \mathrm{dBm}$.

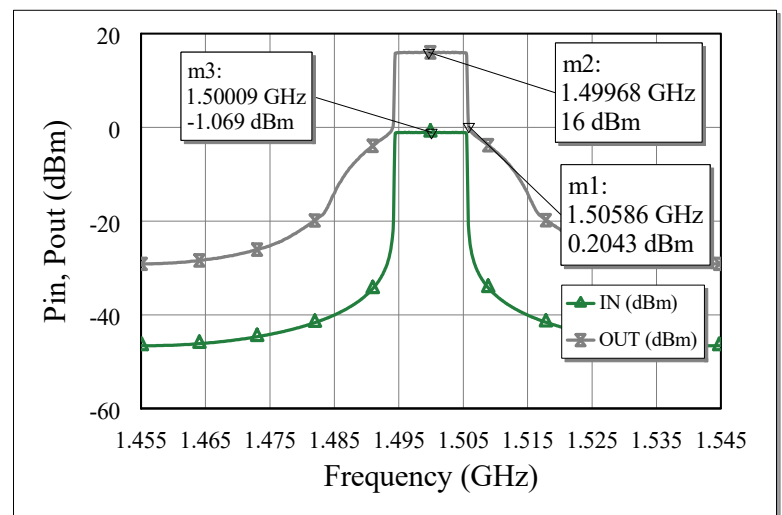

Fig. 7. Simulated spectra of the OFDM signals at the input (green) and output (grey) of the PA.

\section{MEASURED ACPR RESUlts}

We measure the ACPR for the wideband code division multiple access (WCDMA) signal which modulates the $1.5 \mathrm{GHz}$ carrier at the input. The bandwidth of the WCDMA signal is $3.84 \mathrm{MHz}$. The results of the modulated signal measurements are shown in Figs. 8-10 (as screen shots taken from the spectrum analyzer), for the input powers $\left(P_{\text {in }}\right) 0 \mathrm{dBm}, 5 \mathrm{dBm}$, and $15 \mathrm{dBm}$, respectively. These results are summarized in Table I. Note that the $2.7 \mathrm{~dB}$ insertion loss, introduced by the power coupler during measurements, is not compensated for in Figs. 8-10.

Finally, in Table II we present a comparison of the results we obtained with the most representative ones found in the available literature. Because the information about the ACPR is unavailable in some papers, we use $\Delta P$ which we define as the ratio of the maximum power level in main channel and the maximum power level in the adjacent channel. This value can be easily read from the reported graphs. 


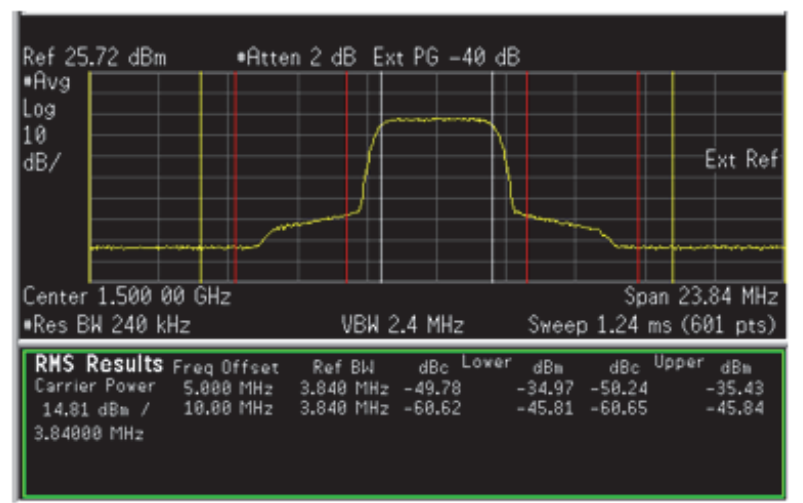

Fig. 8. ACPR measurements for $P_{\text {in }}=0 \mathrm{dBm}$.

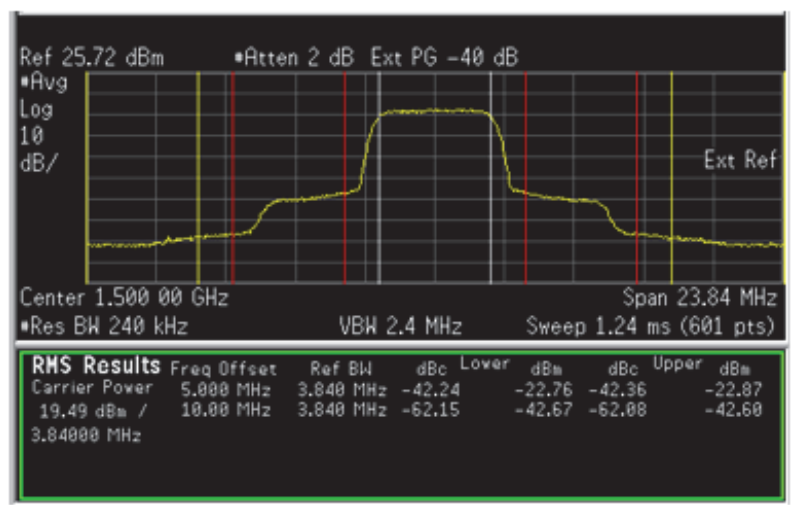

Fig. 9. ACPR measurements for $P_{\text {in }}=5 \mathrm{dBm}$.

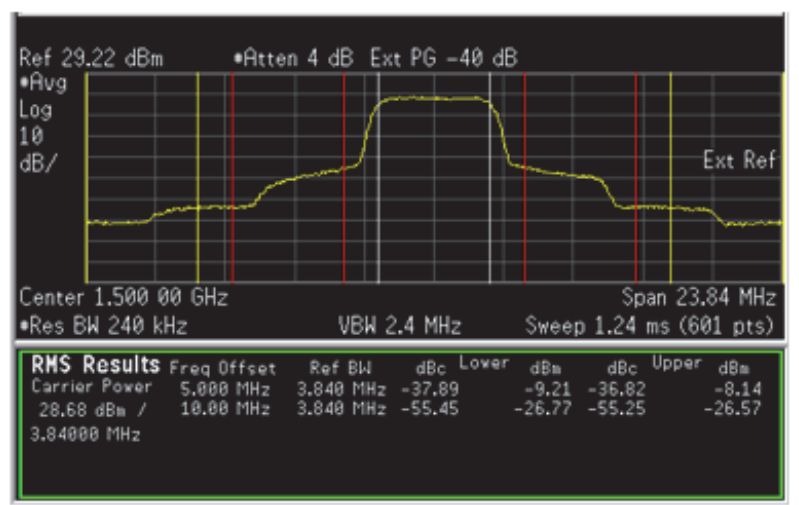

Fig. 10. ACPR measurements for $P_{\text {in }}=15 \mathrm{dBm}$.

TABLE I: ACPR MEASUREMENTS

\begin{tabular}{llllll}
\hline \hline $\begin{array}{l}\text { Pin } \\
{[\mathrm{dBm}]}\end{array}$ & $\begin{array}{l}\text { Pout } \\
{[\mathrm{dBm}]}\end{array}$ & $\begin{array}{l}\text { Id } \\
{[\mathrm{mA}]}\end{array}$ & $\begin{array}{l}\text { ACPR } \\
\text { Lower } \\
{[\mathrm{dBc}]}\end{array}$ & $\begin{array}{l}\text { ACPR } \\
\text { Upper } \\
{[\mathrm{dBc}]}\end{array}$ & $\begin{array}{l}\text { DE } \\
{[\%]}\end{array}$ \\
\hline \hline 0 & 17.5 & 69 & -49.78 & -50.24 & 4.07 \\
5 & 22.2 & 81 & -42.24 & -42.36 & 10.24 \\
15 & 31.4 & 192 & -37.89 & -36.82 & 35.95 \\
\hline \hline
\end{tabular}

- The results include compensation for the $2.7 \mathrm{~dB}$ insertion loss introduced by the power coupler.
TABLE II: COMPARISON WITH LITERATURE

\begin{tabular}{cccccc}
\hline \hline Ref & $\begin{array}{c}\text { Bandwidth } \\
{[\mathrm{MHz}]}\end{array}$ & $\begin{array}{c}\text { PAPR } \\
{[\mathrm{dB}]}\end{array}$ & $\begin{array}{c}\text { Freq. } \\
{[\mathrm{GHz}]}\end{array}$ & $\begin{array}{c}\Delta P \\
{[\mathrm{~dB}]}\end{array}$ & $\begin{array}{c}\text { ACPR } \\
{[\mathrm{dBc}]}\end{array}$ \\
\hline \hline$[6]$ & 10 & 6.6 & 2.14 & $\begin{array}{c}-21 \\
(-45)\end{array}$ & $\begin{array}{c}-22.3 \\
(-45.1)\end{array}$ \\
\cline { 4 - 5 }$[7]$ & 10 & 9.2 & 3.48 & $\begin{array}{c}-28 \\
(-42)\end{array}$ & $\begin{array}{c}/ \\
(-47)\end{array}$ \\
{$[8]$} & 3.84 & 8.51 & 2 & -28 & -30 \\
$\begin{array}{c}\text { This } \\
\text { work }\end{array}$ & 3.84 & 10.5 & 1.5 & -33 & -36 \\
\hline \hline
\end{tabular}

* Some results cited from the literature are approximate since they are obtained from the graph readings.

** Results shown in parentheses are obtained employing digital predistortion (DPD) techniques.

We can conclude from Table II that the ACPR measured for our PA, although at a lower operating frequency, is better (lower) than those reported in [6]-[8] (disregarding the results with DPD).

\section{CONCLUSION}

We characterized some most important nonlinearities of our previously designed and fabricated class-J amplifier [5]. Most of the results presented here are obtained by simulations, except for the single-tone output spectrum and ACPR, which were obtained by measurements. All reported amplifier parameters are on a par with those presented in the available literature on the subject of class-J PAs. Note that some appearing discrepancies can be mostly attributed to different employed operating frequencies, different characteristics of the signals used for driving the power amplifiers during characterization, and different parameters used in simulation techniques.

\section{REFERENCES}

[1] F. M. Ghannouchi, "Power Amplifier and Transmitter Architectures for Software Defined Radio Systems," IEEE Circuits and Systems Magazine, vol. 10, no. 4, pp. 56-63, 2010.

[2] M. Cabarkapa, "Digital predistortion of RF amplifiers using baseband injection for mobile broadband communications," $\mathrm{PhD}$ Dissertation, University of Westminster, London, 2014.

[3] S. C. Cripps, RF Power Amplifiers for Wireless Communications, Artech House, 2006.

[4] S. C. Cripps, P. J. Tasker, A. L. Clarke, J. Lees, J. Benedikt, "On the Continuity of High Efficiency Modes in Linear RF Power Amplifiers," IEEE Microwave and Wireless Components Letters, vol.19, no.10, pp.665-667, 2009.

[5] B. Bukvić and M. Ilić, "Simple Design of a Class-J Amplifier with Predetermined Efficiency," IEEE Microwaves and Wireless Components Letters, vol. 26, no. 9, 2016.

[6] J. Moon, J. Kim, B. Kim, "Investigation of a class-J power amplifier with a nonlinear cout for optimized operation," IEEE Transactions on Microwave Theory and Techniques, vol. 58, no. 11, pp. 28002811, 2010.

[7] J. H. Kim, S. J. Lee, B. H. Park, S. H. Jang, J. H. Jung, C. S. Park, "Analysis of high-efficiency power amplifier using second harmonic manipulation: inverse class-F/J amplifiers," IEEE Transactions on Microwave Theory and Techniques, vol. 59, no. 8, pp. 2024-2036, 2011.

[8] P. Wright, J. Lees, J. Benedikt, P. J. Tasker, S. C. Cripps, "A Methodology for Realizing High Efficiency Class-J in a Linear and Broadband PA," IEEE Transactions on Microwave Theory and Techniques, vol. 57, no. 12, pp. 3196-3204, 2009.

[9] B. Bukvić and M. M. Ilić, "Characterization of nonlinearities in a class-J power amplifier," 2017 25th Telecommunication Forum (TELFOR), Belgrade, 2017, pp. 1-4. 